\title{
Cross-cultural study of accounting students' perception of accounting ethics in Iran and United Kingdom
}

\author{
Mohammadreza Abbaszadeh, Mohsen Moeinizadeh and Mohammadhossein Vadiei \\ Department of Accounting, Ferdowsi University of Mashhad, Iran.
}

Accepted 30 August, 2012

\begin{abstract}
Accountants faces a lot of challenges because of their positions and if they want to achieve society trusts, should regard a series of ethical. Accountants would be able to play their role properly by recognizing some ethical rules and principles because of increasing globalization of economics in international scandal and not community ones. In this research, we compare accounting students' perception of accounting ethics in Iran and United Kingdom using Accounting-specific Defining Issues test (ADIT) and Accounting-specific Multidimensional Ethics scales (AMES). Results of the study indicate that accounting students in United Kingdom are in higher levels of ethical perceptions. In this study, Kohlberg's ethical-cognitive development theory, Rest's four components model and Hofstede's 5 dimensions of culture have been considered as the theoretical basis.
\end{abstract}

Key words: Ethical development, ethical sensitivity, ethical orientation, ethical intention, ethical perception, culture.

\section{INTRODUCTION}

Accounting profession always provides and warrants the needed information for most of the economic decisions; therefore accounting services are crucial in making decisions by all the internal and external users of accounting information.

Regarding the fast approach of trade to globalization, accounting-as the language of business- has to get ready for new challenges. Also the services they offer to the society, accountants need credit and reliability from their clients. With global trade developing, individuals with different nationalities, cultures, traditions and mores get involved the financial events and this compels the accountants to get successfully ready for such a challenging circumstance.

Accountants have no choice but considering accounting ethical principles in order to being trusted by users of information. Therefore, identifying and knowing these principles can lead to promoting the profession in the

${ }^{*}$ Corresponding author. E-mail: mo.moeinizadeh@gmail.com. Tel: +98-915-517-9228. global markets and also to be able to appropriately play their role in their professional position.

\section{Significance of ethics in accounting profession}

After some significant accounting scandals around the world such as Enron, Worldcom, Arthur Andersen, etc. the ethical based investigations in accounting area came into the spotlight.

The common question in all of these investigations was that "why such trained experts cannot distinguish right from wrong and make such disappointing mistakes?"

These scandals clearly indicate that accounting students and also accountants must be aware of accounting ethic principles. So accounting educational centers should consider the ethical principles seriously. As a result, accounting ethical principles and its education programs were discussed in scientific articles and professional literatures (Sharp, 2006).

As business environments become increasingly complex, the number of stockholders who need economic statements and financial information increased. In case of 
providing valid and usable financial reports in order to making reasonable decisions by current and potential stockholders, the accountants as the providers of these reports must follow certain ethical principles; therefore, it is vital for accountants to keep and follow the ethical principles. On the other hand, regarding the current approach around the trade globalization, accounting ethical principles is not considered as a society's problem, but global trade faces the problem because of cultural differences. Companies' increasing tendency into globalization convinces the accounting experts to boost their relationships with the other countries' moral and cultural believes. Since the accounting students are about to be professionals in the future, it is absolutely determining to cross-cultural study on the accounting students' perception through the professional ethical principles (Ho, 2007).

Taking accounting students in United Kingdom and Iran as research subjects, this study investigates whether future accountants from different cultures display differences in their ethical perceptions, which includes ethical development, ethical sensitivity, ethical orientation and ethical intention. So, the main purpose of this study is to compare the difference in the perception of accounting ethics for accounting students from different cultural backgrounds.

\section{LITERATURE REVIEW}

Several researchers have studied differences in perception of the accounting ethical principles in various papers. Eynon et al. (1996) used defining issues test (DIT) to compare the abilities of ethical reasoning of United States and Irish accounting students and found that P-scores of these two countries were similar to each other.

Arzova and kidwell (2004) studied the ethical attitudes of Turkish accounting students compared to Australian and Irish accounting students' ethical behavior. The results revealed that despite the cultural variables that might suggest students from Turkey would display higher unethical behavior, the opposite results were obtained. Males were found to be more likely to take unethical actions. Collectivism culture did have some effect on how students would behave when refusing the unethical offer from a friend.

Venezia (2005) examined United States and Taiwanese accounting students' level of ethical reasoning abilities by using the DIT-2. She found that Taiwanese accounting students possessed higher levels of ethical reasoning than students in the United States and concluded that students in different countries might have different ethical development.

O'leary and Mohamad (2005) studied the ethical attitudes of final-year accounting students in Malaysia and Australia. They found significant differences in ethical attitudes of final-year accountancy students from these two countries; that is ethical attitudes are influenced by the nationalistic trait. For instance, Malaysian students were more likely to cheat on an exam than participate in corruption.

Taking accounting students in the United States and Taiwan as research subjects, Ho (2007) investigates whether future accountants from different cultures display differences in their ethical perceptions, ethical intention, and ethical orientation. Moreover, the study attempts to explore the possible cultural and other factors that influence the differences of accounting students' ethical perception between the United States and Taiwan. Results of the study indicate significant differences in ethical sensitivity, ethical development, ethical intention, and ethical orientation between the United States and Taiwanese accounting students. Hofstede's cultural factors to some extent reveal significantly influences on students' ethical perception, but with a situationalcontingent pattern.

Chung et al. (2008) studied the perception of ethical principles among the Eastern Asian countries (China, Korea and Japan) and Americans' business students. The results showed that American students have a greater perception of ethical problems in business and that is why they were consent with the need to ethical behavior.

Ethical perception on tax evasion among American and Hong Kong students were studied by Simon et al. (2008). The results indicated despite the both countries' students consider the tax evasion as ethical at some special circumstances, but generally this is unethical to do. Also, the results showed a big difference in points of view between the two countries' students.

Jabbari and Royayee (2010) investigated the effect of Hofstede's cultural dimensions on the ethical perceptions of the Iranian, American and Taiwanese accounting students through a comparative study. The results indicated that there is a significant difference between ethical development, intention and orientation among the Iranian, American and Taiwanese accounting students.

\section{The theoretical basis}

Kohlberg's ethical-cognitive development theory, Rest's four components model and Hofstede's 5 dimensions of culture have been considered as the theoretical basis in this paper.

\section{Kohlberg's ethical-cognitive development theory}

Kohlberg's theory of cognitive moral development (1969; 1981 ; 1984) has been widely used in understanding the reasons that people use in making moral judgments. Kohlberg (1969) defines moral reasoning as the judgment 


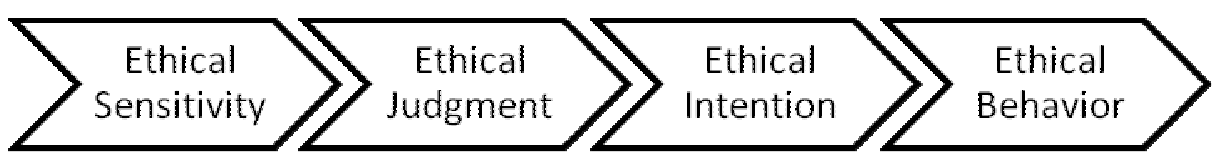

Figure 1. Summary of Kohlberg's theory.

about right and wrong; moral development is the level of maturity of moral reasoning. He also defines a subject's level of moral reasoning as the reasoning used to defend one's position when faced with a moral dilemma. Up to the present, Kohlberg's cognitive moral development theory is the most widely used theory in analyzing individuals' ethical development, though some researchers argue that it has its limits. Kohlberg divides moral development into tree major levels and stages as follows:

Level I: Pre-conventional morality

Stage 1: Obedience: You do what you are told primarily to avoid punishment.

Stage 2: Instrumental egotism and simple exchange: Let's make a deal or only consider the costs and/or benefits to one self.

Level II: Conventional morality

Stage 3: Interpersonal concordance: Be considerate, nice and kind and you will get along with people. Focus is on cooperation with those in your environment.

Stage 4: Social system and conscience: everyone in society is obligated to and is protected by the law. Focus is on cooperation with society in general.

Level III: Post-conventional morality

Stage 5: Social consensus: you are obligated by whatever arrangements are agreed to and by due process and procedure. Focus is on fairness of the law or rule as determined by equity and equality in the process of developing rule.

Stage 6: Non-arbitrary social cooperation: rational and impartial people would view cooperation as moral focus is on fairness of the law or rules derived from general principles of just and right as determined by rational people.

Based upon longitudinal studies of young boys, Kohlberg argues that as individuals mature, so too does their ethical judgment. Kohlberg proposes that as people mature and acquire more education and experience, their moral reasoning develops along with a well-defined sequence of stages.

According to Kohlberg's cognitive moral development theory, cognitive moral development is the extent to which consideration should ideally be given to resolve a particular ethical dilemma, and it describes the sophisticated cognitive moral structure that an individual is potentially capable of utilizing.

\section{Rest's four components model}

Kohlberg's theory describes the individual's ethical development, but it does not show how ethical development results in ethical action. As ethical development alone is inadequate to produce behavior, building upon Kohlberg's theory, Rest (1986a) developed the four-component model of ethical action that describes the process of ethical decision making. This model consists of four components and shows how ethical sensitivity leads to ethical behavior (Figure 1).

Based on Rest's model, ethical sensitivity is the first step toward making an ethical decision. Ethical sensitivity is the ability to recognize an existing ethical problem, to interpret the situation, and to understand how a proposed action would affect others. The ability to recognize and correctly evaluate the ethical dilemmas in decision situations is a necessary prerequisite to good ethical decisions. Accounting professionals cannot be expected to make consistently suitable ethical choices if they are unable to identify ethical criteria and evaluate them in a given ethical situation. Ethical intention, the third component of Rest's model, is the degree of commitment to taking an ethical action. Accounting professionals will be more likely to act ethically while they possess higher ethical intention.

Rest's four component model of ethical action strongly influences research accounting ethics. Researchers have found it to be a valid model of ethical decision-making in accounting on a global scale. Also, there are different findings about relationship between these components and individuals' ethical behaviors. This model is the most widely accepted model about ethical action in psychology.

\section{Hofstede's 5 dimensions of culture}

Hofstede's (2005) research suggests that there are five dimensions of culture including:

1. Power distance (PDI): The extent to which the less powerful members of institutions and organizations within a country expect and accept that power is unequally.

2. Uncertainty avoidance (UAI): The extent to which the members of a culture feel threatened by ambiguous or unknown situations.

3. Indvidualism/collectivism (IDV): Societies in which the ties between individuals are loose, and everyone is expected to look after himself/herself and his/her immediate 
family.

4. Masculinity/femininity (MAS): Masculine cultures are those that value material achievement and assertiveness, whereas feminine cultures tend to place more value on qualities such as interpersonal relationships and concern for the weak.

5. Short/long term orientation (LTO).

As this study compares ethical perceptions for accounting students from the United Kingdom and Iran, a comparison of the national culture index scores and ranking of the United Kingdom and Iran on the five cultural dimensions from Hofstede's International Business Machines (IBM) research is shown in Table 2. These scores only describe their relative differences on each dimension, not their absolute values (Hofstede, 2001).

As hofstede's typology of culture has been widely used in cross-cultural research, it is taken as a theoretical basis of this cross-cultural study. Based on the theoretical basis, the variables of this paper defined as follows:

Ethical development: A subject level of moral reasoning as the reasoning used to defend one's position when faced with a moral dilemma.

Ethical sensitivity: Ability of the decision maker to recognize an existing ethical problem, interpret the situation, and take various roles to understand how that proposed action would affect others.

Ethical orientation: Ability to realize which ethical philosophy is the best to explain the ethical problems.

Ethical intention: The degree of commitment with which one will conduct ethical action and behaviors, the extent to which one will put more emphasis on moral values than other values, or the extent to which taking charge to bring about ethical results.

Ethical perception: Including ethical development, ethical sensitivity, ethical intention, and ethical orientation.

Culture: Is a set of values and beliefs that a group of people have developed over time as a consequence of their relationship with their environment.

\section{RESEARCH DESIGN AND METHODOLOGY}

\section{Subjects}

Accounting students from United Kingdom and Iran were solicited to act as subjects. The Iranian samples were picked among governmental universities which represent undergraduate accounting courses. To gather data in England, the questionnaires (via office excel form) were sent to all the universities presenting the equivalent accounting undergraduate courses which were sent back after answering by the students. 160 questionnaires from Iran and 126 ones from England were collected.

\section{Research question}

Are there any differences in ethical perceptions of the United Kingdom and Iranian accounting students based on their cultures background?

\section{Research hypotheses}

In this paper, six hypotheses are being tested:

$\mathbf{H}_{1}$ : There are significant differences in ethical development of accounting ethics between accounting students from United Kingdom and those from Iran.

H2: There are significant differences in ethical sensitivity of accounting ethics between accounting students from United Kingdom and those from Iran.

$\mathbf{H}_{3}$ : There are significant differences in ethical orientation of accounting ethics between accounting students from United Kingdom and those from Iran.

$\mathbf{H}_{4}$ : There are significant differences in ethical intention of accounting ethics between accounting students from United Kingdom and those from Iran.

$\mathbf{H}_{5}$ : There are significant differences in ethical perception of accounting ethics between accounting students from United Kingdom and those from Iran.

$\mathbf{H}_{6}$ : Individualism/collectivism and masculinity/femininity dimensions will have more influence on accounting students' ethical perceptions than other hofstedes' dimensions.

\section{Survey instrument}

The instruments used in the study consist of the Accountingspecific Defining Issues Test (ADIT), which is used to assess participants' moral reasoning ability, the Accounting-specific Multidimensional Ethic Scales (AMES), which is employed to measure participants' ethical sensitivity, ethical intention, ethical intention, and ethical orientation when facing ethical dilemmas (Reidenbach and Robin 1988) and to measure accounting students' scores on hofstede's five cultural dimensions, the Values Survey Module 1994 (VSM94) used in the survey.

\section{Test instrument validity and reliability}

It is essential in a cross-cultural study that the version of a questionnaire presented to subject from different countries be linguistically equivalent (Rest, 1986b). Even slight differences in translation may have rather dramatic effect on the result. Ensuring the equivalence of subjects' responses across countries is perhaps the most difficult task in conducting a cross-cultural study (Thorne, 2000). So the instruments are translated and back translated bilingual teachers. Also this study uses Cronbach's alpha to assess the reliability of the questionnaire survey used (Cronbach, 1951). To calculate the Cronbach's alpha coefficient, the following relation is used (Sarmad et al., 2001):

$\alpha=\left(\frac{k}{k-1}\right)\left[1-\frac{\Sigma s_{i}^{2}}{s^{2}}\right]$

$S_{i}: i^{\text {id }}$ question variance

$\mathrm{S}^{2}$ : total questions variance

$\mathrm{K}$ : number of the questionnaire's questions

The validity for each of the instruments used in study has been confirmed respectively by Thorne (2000), and Cohen et al. (1993a). 
Table 1. Demographic information

\begin{tabular}{lccc}
\hline & United Kingdom & Iran & Total \\
\hline Age & & & \\
Average & 23.51 & 22.79 & \\
Standard deviation & 2.03 & 3.29 & \\
& & & \\
Gender & & 50 & 105 \\
Male & 55 & 110 & 181 \\
Female & 71 & & \\
Ethics courses & & 64 & 92 \\
Yes & 28 & 96 & 194 \\
No & 98 & & \\
& & & \\
Religion & & 160 & 166 \\
Muslim & 6 & - & 102 \\
Christian & 102 & - & 4 \\
Buddhist & 4 & - & 14 \\
None & 14 & & \\
\hline
\end{tabular}

Table 2. Computed cultural value scores of the five Hofstede dimensions.

\begin{tabular}{lcccc}
\hline \multirow{2}{*}{ Dimensions } & \multicolumn{2}{c}{ United Kingdom } & \multicolumn{2}{c}{ Iran } \\
\cline { 2 - 5 } & Hofstedes' index value $^{\mathbf{1}}$ & Thissurvey & Hofstedes' index value $^{\mathbf{1}}$ & Thissurvey $^{\text {Thy }}$ \\
\hline PDI & 35 & 32 & 58 & 49 \\
UAI & 35 & 82 & 59 & 70 \\
IDV & 89 & 67 & 41 & 59 \\
MAS & 66 & 39 & 43 & 61 \\
LTO & 25 & 28 & - & 36 \\
\hline
\end{tabular}

${ }^{1}$ http://www.geert-hofstede.com

\section{Data collection}

One hundred and sixteen participants of Iran and one hundred and twenty six participants of the United Kingdom completed the surveys and all questionnaires analyzes by professional statisticians. Demographic information is shown in Table 1.

In this study, we re-calculated culture-determined value scores of accounting students from the United Kingdom and Iran using VSM94 instead of using Hofstede's scores because Hofstede's study was more than 30 years old so may not be current enough to apply to this study. Table 2 presents the results of analyzing VSM94 in this study comparing with Hofstede's index values:

As Hofstede (2001) suggests, it may be inappropriate to interpret the changes between current results and Hofstede's earlier findings within the same country.

To analyze the questionnaire results, the analyzing methods are: $\mathrm{T}$ - test and regression analysis.

T- test is a statistical method which use to compare means equality hypothesis at two societies with different mean and variances.

Multiple regression analysis is a statistical procedure for determining the magnitude of the relationship between a dependent variable and combination of several predictor variables and is also employed in this study to test hypotheses $\mathrm{H} 6$ by:
Ethicalper ception $=$

$$
\begin{gathered}
\beta_{0}+\beta_{1} \cdot P D I+\beta_{2} \cdot U A I+\beta_{3} \cdot I D V+\beta_{4} \cdot M A S+\beta_{4} \cdot L T O \\
+\beta_{6} . \text { Age }+\beta_{7} . \text { Gender }+\beta_{8} . \text { Course }+\beta_{9} . \text { Re ligion }
\end{gathered}
$$

\section{RESULTS ANALYSIS}

To examine the hypotheses, we constitute $\mathrm{HO}$ and $\mathrm{H} 1$ separating the variables as follows:

$\mathbf{H}_{0}$ : There are no differences in ethical development of accounting ethics among two countries' accounting students.

$\mathbf{H}_{1}$ : There are differences in ethical development of accounting ethics among two countries' accounting students.

Table 3 represents descriptive information on the ethical 
Table 3. Descriptive information on the ethical different dimensions of United Kingdom and Iranian students

\begin{tabular}{lcccc}
\hline \multirow{2}{*}{ Variable } & \multicolumn{2}{c}{ United Kingdom } & \multicolumn{2}{c}{ Iran } \\
\cline { 2 - 5 } & Mean & Standard deviation & Mean & Standard deviation \\
\hline Ethical development & 66.0236 & 6.48419 & 62.7 & 4.29245 \\
Ethical sensitivity & 3.4117 & 0.77573 & 2.9658 & 0.89902 \\
Ethical orientation & 4.0821 & 1.06683 & 3.6743 & 1.29867 \\
Ethical intention & 2.8582 & 1.2335 & 2.1833 & 1.17406 \\
Ethical perception & 3.4508 & 0.87455 & 2.9414 & 0.9782 \\
\hline
\end{tabular}

Table 4. Results of the T- test separating variables for the two countries' students.

\begin{tabular}{lcccccc}
\hline \multirow{2}{*}{ Variable } & \multicolumn{4}{c}{ T- test } & \multicolumn{3}{c}{$\begin{array}{c}\text { Confidence distance for the means } \\
\text { difference with confidence level of 95\% }\end{array}$} \\
\cline { 2 - 7 } & $\begin{array}{c}\mathrm{t}- \\
\text { statistic }\end{array}$ & $\begin{array}{c}\text { Degree of } \\
\text { freedom }\end{array}$ & $\begin{array}{c}\boldsymbol{P} \text { value } \\
\text { value }\end{array}$ & $\begin{array}{c}\text { Means } \\
\text { difference }\end{array}$ & Upper limit & Lower limit \\
\hline E Development & -5.032 & 264 & 0.000 & -3.32358 & -2.02298 & -4.62419 \\
E Sensitivity & -4.178 & 264 & 0.000 & -0.44589 & -0.23576 & -0.65601 \\
E Orientation & -2.687 & 264 & 0.008 & -0.40776 & -0.10895 & -0.70657 \\
E Intention & -4.498 & 264 & 0.000 & -0.6749 & -0.37947 & -0.97032 \\
E Perception & 4.335 & 264 & 0.000 & -0.50947 & -0.27809 & -0.74086 \\
\hline
\end{tabular}

Table 5. variance analysis for sixth hypothesis.

\begin{tabular}{lccccc}
\hline Model & Sum of squares & Degree of freedom & Squares mean & F statistic & $\boldsymbol{P}$-value \\
\hline Regression & 33.065 & 10 & 3.306 & 3.984 & 0.000 \\
Residual & 187.546 & 226 & 0.830 & & \\
Sum & 220.610 & 236 & & & \\
\hline
\end{tabular}

Perception different dimensions separating United Kingdom and Iranian students.

Table 4 represents the results of the T- test for the United Kingdom and Iranian students. As shown in Table 4 , since the $P$-value is less than $\alpha=0.05$ in all cases, it can be inferred that there's difference in any dimension of English and Iranian students' ethical perception, so $\mathrm{H} 1$ is accepted. The result of model's fit is shown in Table 5.

As it is shown in Table 5, $P$-value is less than 0.05 and we can reject null hypothesis, and it means there are relations between dependants and independents variable. So we analyze the regression. The result of regression analysis is shown in Table 6.

\section{DISCUSSION AND RESULTS}

First, the results of the VSM94 in the study indicate that there are significant differences between the United Kingdom and Iranian accounting students on Hofstede's dimensions. The United Kingdom students obtained higher scores on the uncertainty avoidance index (UAI) and Individualism (IDV) dimensions. This finding confirms the premise that there exist cultural differences between the two groups, and supports further investigations of possible cultural factors influencing the differences in students' ethical perceptions.

Second, considering data in Table 3, by using the ADIT with three scenarios (Thorne, 2000), the research hypothesis $\mathrm{H} 1$ is supported that there are significant differences in ethical development of accounting ethics between accounting students from the United Kingdom and those from Iran. The mean ADIT P-scores of United Kingdom respondents (66.0236) are higher than their Iranian counterparts (62.7) in the study.

Third, by using the AMES with three scenarios, the research hypothesis $\mathrm{H} 2, \mathrm{H} 3$ and $\mathrm{H} 4$ is supported that there are significant differences in overall ethical sensitivity, orientation and intention of accounting ethics between accounting students from the United Kingdom and those from Iran. As it is shown in Table 3, the mean AMES P-scores of United Kingdom respondents for ethical sensitivity, orientation and intention is higher than their Iranians'.

Fourth, ethical perception is combination of ethical development, sensitivity, orientation and intention (Ho, 
Table 6. Results of regression analysis.

\begin{tabular}{lccccc}
\hline Factor & Standard deviation & standardized coefficient & $\mathbf{t}$ & Sig. & VIF \\
\hline Age & 0.023 & -0.005 & -0.073 & 0.942 & 1.097 \\
Gender & 0.131 & 0.213 & 3.229 & 0.001 & 1.154 \\
Course & 0.133 & 0.06 & 0.955 & 0.341 & 1.059 \\
Religion & 0.071 & 0.066 & 0.819 & 0.414 & 1.725 \\
PDI & 0.001 & -0.028 & -0.447 & 0.655 & 1.06 \\
UAI & 0.001 & -0.045 & -0.694 & 0.489 & 1.105 \\
MAS & 0.001 & -0.201 & -2.642 & 0.009 & 1.108 \\
IDV & 0.001 & 0.059 & 0.924 & 0.356 & 1.085 \\
LTO & 0.003 & -0.194 & -2.482 & 0.014 & 1.059 \\
\hline
\end{tabular}

2007), so it can be presumed that United Kingdom accounting students' ethical perception is higher than Iranians'. The results of the fifth hypothesis test (mean scores for United Kingdom accounting students $=3.4508$ and for Iranians'=2.9414) are also indicating higher English students' ethical perception rather than Iranians'. This results followed previous studies.

In sixth hypothesis, it is presumed that Individualism/ collectivism and masculinity/femininity dimensions have more influence on accounting students' ethical perceptions than other hofstedes' dimensions. To test this hypothesis, this study builds a regression equation that take all accounting students' ethical perception as the dependent variable, hofstede's five cultural dimensions as independent variables, and age, gender, exposure to ethics courses and religious orientation as control variables. Due to the $P$-value in variance analysis which is less than 0.05 (Table 5), we can conclude that there are some independent variables which affect ethical perception that are Masculinity/ femininity (MAS), long term orientation (LTO) and gender. We can also add this points that these variables directly influence on ethical perceptions and the effects of MAS is more than LTO. So, sixth hypothesis is partially accepted.

\section{CONCLUSION AND IMPLICATIONS}

Considering the results, the following suggestions come as follows:

1. With a regard that accounting students will serve as professional accountants and auditors in future, a convenient ethical perception can prevent many economic corruptions. So universities should prepare appropriate services promoting ethical perception level through separate dimensions of ethical development, sensitivity, orientation and intention. Officials can also be helpful through setting appropriate courses.

2. Considering economic environment globalization and multinational institution's development, it is better for educating approach to focus on international goals (venezia 2008). So it is suggested to the curriculum planners and relevant institutions to revise the accounting topics charts and plan based on ethical principles and international professional behavior ethics. Also, based on 6th hypothesis' results, it can be stated that we should consider MAS and LTO in curriculum planning $(\mathrm{Ho}$, 2007).

3. It is suggested to the accounting professors and teachers to emphasize on the professional ethical principles education as one of the primary basis in accounting courses. This can be useful when future accountants face challenges. Also some rules should be legislated by relevant institutes (for example, Financial Accounting Standards Board) to emphasize on passing the ethical courses and professional behavior ethics by students at universities and learning centers. These institutions can help the students and professional accountants to be updated by holding some tests regularly.

4. International institutes should consider ethical perceptions and ethical behaviors beside technical abilities in order to employ responsible and expert accountants. According to Gowthorpe and Blake (1998) the higher an accountant's ethical perception level is, the better he acts when confronting problems and issues.

\section{REFERENCES}

Arzova SB, Kidwell LA (2004). The ethical behaviors of final year Turkish accountancy students compared with their Australian and Irish counterparts. Int. J. Account. Audit. Perform. Eval. 1(3):385-400.

Chung KY, Eichenseher JW, Taniguchi T (2008). Ethical Perception of Business Students: Differences between East Asia and the USA and Among Confucian Cultures. J. Bus. Ethics 79(1):121-132.

Cronbach L (1951). Coefficient alpha and internal structure of tests. Psychometrika 16(3):297-334.

Cohen JR, Pant LW, Sharp DJ (1993a). A validation and extension of a multidimensional ethics scale. J. Bus. Ethics 12(1):13-26.

Eynon G, Hill NT, Stevens KT, Clarke P (1996). An international comparison of ethical reasoning abilities: Accounting students from Ireland and the United States. J. Account. Educ. 14(4):477-492.

Gowthorpe C, Blake J (1998). Ethical issues in accounting. New York, NY: Routledge.

Ho YH (2007). Undergraduate accounting students' perception of 
accounting ethics: A cross-cultural comparative study, Specialized for the degree of doctor of philosophy, The faculty of the graduate school of the University of Minnesota.

Hofstede G (2001). Culture's consequences: Comparing values, behaviors, institutions, and organizations across nations ( $\left.2^{\text {nd }} e d.\right)$. Thousand Oaks, CA: Sage.

Hofstede G, Hofstede GJ (2005). Cultures and organizations: software of the mind (2nd ed.). McGraw-Hill. http://en.wikipedia.org/wiki/Sampling_(statistics)\#Convenience_sampl ing. http://www.geert-hofstede.com.

Jabbari H, Royayee R (2010). The effect of culture on the ethical perceptions of accounting students (Multi-cultural Research). Specialized PhD Dissertation in Accounting Field, Islamic Azad University of Tehran, IRAN.

Kohlberg $L$ (1969). Stage and sequence: The cognitive developmental approach to socialization. In: Goslin DA (Ed.), Handbook of socialization theory and research. Chicago: Rand- McNally. pp. 347480.

Kohlberg $L$ (1981). The meaning and measurement of moral development (Heinz Werner Lecture series, Vol.13. Worcester MA: Clark University Press.

Kohlberg L (1984). Psychology of moral development. San Francisco, CA: Harper \& Row Publisher.

O'Leary C, Mohamad S (2005). A bi-national study of accountancy students' ethical attitudes (Working Paper 2005 - 013). Brisbane, Australia: Queensland University of Technology, School of Accountancy.
Reidenbach RE, Robin DP (1988). Some initial steps toward improving the measurement of ethical evaluation of marketing activities. J. Bus. Ethics 7(11):871-879.

Rest JR (1986a). Moral development: Advances in research and theory. New York, NY: Praeger Publishers.

Rest JR (1986b). Manual for the Defining issues test. Minneapolis, MN: University of Minnesota.

Sarmad Z, Bazargan A, Hejazi E (2001). Research method in the Behavioral Sciences. Agah publishing co: Tehran.

Sharp DJ (2006). Cases in business ethics. Thousdands Oaks, CA: Sage.

Simon SM, Robert W, Annie YS (2008). A Comparative Study on Perceived Ethics of Tax Evasion: Hong Kong Vs the United States. J. Bus. Ethics 77(2):147-158.

Thorne $L$ (2000). The development of two measures to assess accountants' Prescriptive and deliberative moral reasoning. Behav. Res. Account. 12:139-169.

Venezia CC (2005). The ethical reasoning abilities of accounting students. J. Am. Acad. Bus. 6(1):200-207.

Venezia CC (2008). Are Female Accountants More Ethical Than Male Accountants: A Comparative Study betweenthe U.S. And Taiwan. J. Int. Bus. Econ. Res. 7(4). 